\title{
La amenaza inglesa en la novela hispanoamericana, 1841-1982
}

\section{The English Threat in the Hispanic-American Novel 1841-1982}

\section{A ameaça inglesa na novela Hispano-americana}

\author{
Charles B. Moore \\ Profesor de Literatura Hispanoamericana \\ Gardner-Webb University \\ Estados Unidos de América \\ Recibido: 3/5/2016-Aceptado: 15/07/2016 \\ DOI: http://dx.doi.org/10.15359/tdn a.32-60.2
}

\section{Resumen}

Desde las primeras épicas y crónicas de la Conquista, la presencia y amenaza subyacente de Inglaterra en Hispanoamérica han sido constantes. Este artículo examina la evolución de esta historia en cinco novelas hispanoamericanas de 1841-1982. Al final del siglo XX veremos si el problema sigue o si finalmente muere ante la presión de un mundo otra vez en caos y en búsqueda de un nuevo comienzo, libre de las cadenas del pasado.

Palabras clave: Inglaterra, amenaza, novela hispanoamericana, siglos XIXXX, América Latina, literaturas

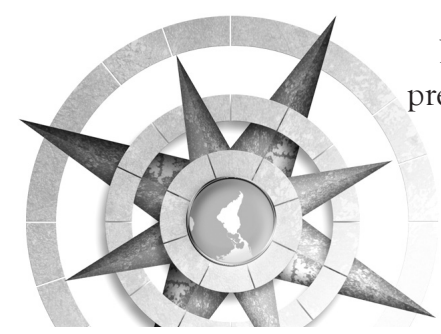

\section{Abstract}

Since the very first epics and chronicles of the Conquest, the presence and underlying threat of England in Hispanic America has been constant. This article examines the evolution of this history in five Hispanic American novels written between 1841 and 1982. Our purpose is to see whether the problem continues at the end of the 20th century or whether it finally expires given the pressure of a world that is once again facing chaos and is in search of a new beginning, free from the chains of the past.

Keywords: England, threat, Spanish America novel, 19th-20th centuries, Latin America, Literatures

\section{Resumo}

Desde as primeiras crônicas e epicas da Conquista, a presença e ameaça subjacente da Inglaterra na América 
Latina têm sido constantes. Este artigo examina a evolução desta história em cinco novelas hispano-americanas de 1841 1982. No final do século XX, vamos ver se o problema persistir ou se finalmente termina devido à pressão de um mundo em caos em busca de um novo começo, livre das grilhetas do passado.

Palavras chave: Inglaterra, ameaça, romance hispano-americano, séculos XIX e XX, America Latina, literaturas

Muchos escritores a través de los siglos han documentado la intrusión de los ingleses en las colonias hispanoamericanas de América. En 1589, el neogranadino Juan de Castellanos dedica la Parte IV entera de su mega-épica, Elegías de varones ilustres de Indias, al saqueo de Cartagena por el famoso pirata inglés Francisco Draque. Otras historias del siglo XVII, como Historia General (1601-15), de Antonio de Herrera, o la inédita continuación de las mismas por Pedro Fernández de Pulgar, corroboran las ruines hazañas del notorio corsario (González, 1589: LVI).

En el siglo XVIII la voluminosa épica anacrónica Lima fundada (1732), del peruano Pedro Peralta y Barnuevo, no solamente recoge el tema de los ataques de Draque en la Española (1586) y Santa Marta (1595), sino también las atrocidades de otros piratas ingleses como Thomas Candisch
(Estrecho de Magallanes), John Oxenham (Darién), Henry Morgan (Panamá, 1670), John Cliperton (Perú, 1720), el holandés Edward David (Darién, 1685) y los contrabandistas franceses que minaron la estabilidad de las colonias españolas (Peralta y Barnuevo, 1732: 347-471).

A principios del siglo XIX los viajes y escritos naturalistas del alemán Alexander von Humboldt fascinaron a los europeos con visiones de una América primordial y prístina (Pratt, 2008, p. 117). Como resultado, multitudes de equipos de avance e inversionistas ingleses descendieron sobre el continente en busca de recursos naturales, mano de obra y mercados en la venidera época post-española (Pratt, 2008; Winn, 1976).

En la literatura de la época estas personas se presentan muchas veces en los momentos más inesperados o inoportunos. En El matadero de Esteben Echeverría (1838), por ejemplo, mientras los jinetes del dictador Rosas persiguen al joven unitario atropellan por casualidad a «cierto inglés, de vuelta de su saladero ... a la sazón» (1982, p. 17) y lo dejan medio hundido en el fango del pantano. Y cuando la policía entra súbitamente a la pulpería para arrestar a Martín Fierro y los otros gauchos, el narrador de Martín Fierro (1872) explica que

32 La amenaza inglesa en la novela hispanoamericana, 1841-1982 Charles B. Moore 
«hasta un inglés sanjiador / que decía en la última guerra / que él era de Inca-la-perra / y que no quería servir, tuvo también que juír / a guarecerse en la sierra» (1973, p. 34).

Al respecto, Inglaterra invadió el Río de la Plata en 1806 y 1807 y, con Francia, abiertamente anunció sus intenciones de apoderarse de las ex colonias españolas (Pratt, 2008; Winn, 1976). Como el diplomático británico George Canning lo expresó en 1824, «Spanish America is free; and if we do not mismanage our affairs sadly, she is English» ${ }^{1}$ (citado por Winn, 1976, p. 102; énfasis de Winn). Frente a este peligro, Juan María Maury y Benítez publicó La agresión británica en 1806 para apoyar a los españoles y advertir a sus compatriotas sobre las codiciosas intenciones de los ingleses (French, 2005). Aunque casi olvidada hoy, la obra influyó mucho en Andrés Bello, quien escribió su famosa Silva a la agricultura de la zona tórrida en 1826 (French, 2005). Curiosamente, sin embargo, en su elogio a la belleza bucólica de la región el astuto Bello calla la invasión inglesa de 1806, el involucramiento inglés en el movimiento independentista hispanoamericano y los numerosos ingleses que ya poseen minas de oro y plata abandonadas por los españoles

1 N.T.: «Hispanoamérica es libre, y si no manejamos mal nuestros asuntos, es inglesa"
(French, 2005). Sabe que debe tratar a los ingleses con cuidado para asegurar su apoyo contra los españoles e, igual que otras élites criollas, guarda silencio sobre su creciente influencia comercial, militar y política en América (French, 2005). Aunque la relación entre Gran Bretaña y Latinoamérica fue uno de los factores más importantes en el desarrollo de la región, se ha notado también su ausencia en la literatura e incluso en los escritos políticos del siglo XIX (French, 2005).

Como resultado de este silencio, Inglaterra logró apoderarse sutilmente de los débiles mercados de Hispanoamérica a través de lo que se ha llamado un imperio informal invisible (French, 2005; Winn, 1976; Hidalgo, 2007). Por ejemplo, la breve ocupación inglesa de Montevideo en 1806 fue un gran éxito comercial, ya que diseminó un gusto por «the thin, showy and low priced goods of English manufacture" throughout the Plata Basin»² (Winn, 1976, p. 101). $\mathrm{Y}$ sin ninguna intervención militar siquiera, los británicos determinaban la política doméstica e internacional de México debido a su control de los críticos servicios públicos y el financiamiento de inversiones (Hidalgo, 2007, p. 319). Irónicamente, este

2 N.T.: «los productos ligeros, llamativos y de bajo precio de la manufactura inglesa» 
imperio no fue «visible» hasta que Inglaterra empezó a debilitarse después de la Primera Guerra Mundial (French, 2005). En este momento los cuentos de Horacio Quiroga (1918. 21) y las novelas telúricas - La vorágine (1924) de José Eustasio Rivera, Don Segunda Sombra (1926) de Ricardo Güiraldes y Doña Bárbara (1929) de Rómulo Gallegos- expusieron el neocolonialismo existente y sugirieron una nueva negociación de los recursos naturales de Hispanoamérica (French, 2005).

Este estudio explorará cinco novelas que abarcan el apogeo del imperio - Sab (1841) de la cubana Gertrudis Gómez de Avellaneda, Amalia (1850) del argentino Jorge Mármol, María (1867) del colombiano Jorge Isaacs, Cecilia Valdés (1882) del cubano Cirilo Villaverde y El inglés de los güesos (1924) del uruguayo-argentino-irlandés Benito Lynch- para saber si se guardó tanto silencio sobre los ingleses como se ha creído. El estudio concluye con dos novelas publicadas más de medio siglo después - La guerra del fin del mundo (1981) del peruano Mario Vargas Llosa y La casa de los espiritus (1982) de la chilena Isabel Allende- para mostrar la larga trayectoria del tema inglés y su sorprendente desenlace eventual en el post-boom latinoamericano.

\section{Sab y María: la educación, la economía y la amenaza familiar}

Gertrudis Gómez de Avellaneda presenta la nueva economía mercantilista con ánimo de lucro por medio de los hombres ingleses de la familia Otway en su novela antiesclavista Sab (Ibarra, 2011). Al adquirir tierra y riqueza en la Cuba del siglo XIX ellos simbolizan el «desarrollo» neocolonialista británico a nivel mundial (Ward, 2002). Sobre esta situación el narrador le explica al lector:
Sabido es que las riquezas de Cuba atraen en todo tiempo innumera- bles extranjeros que con mediana industria y actividad no tardan en enriquecerse de una manera asom- brosa para los indolentes isleños, que satisfechos con la fertilidad de su suelo, y con la facilidad con que se vive en un país de abundancia, se adormecen por decirlo así, bajo su Sol de fuego, y abandonan a la codicia y actividad de los europeos todos los ramos de agricultura, co- mercio, e industria, con los cuales se levantan en corto número de años innumerables familias (Gó- mez, 2008, p. 33).

A diferencia de muchos de sus contemporáneos cubanos, Gómez critica la llamada «modernización» económica de la isla que traen estos personajes blancos. Este tipo de «progreso»no solamente 
puede destruir la economía tradicional de la isla, sino también la estructura y felicidad familiares (Ibarra, 2011).

A pesar de su vasto y lucrativo comercio de lienzos en Puerto Príncipe y Estados Unidos, el recién llegado padre Jorge Otway se endeuda en Cuba. Antes de que su ruina se descubra, desea casar a su pueril e indeciso hijo Enrique con la bella Carlota Bellavista, hija de unos supuestos hacendados criollos. Pero «el codicioso inglés» (Gómez, 2008, p. 38) pronto descubre que los bienes de la familia Bellavista son de solamente «una módica fortuna» (p. 61), por lo cual ya no quiere que Enrique se case con Carlota mientras haya otras mujeres más ricas que ella. Le explica a su hijo que el matrimonio es una transacción comercial y que un buen comerciante se casa por mera especulación y conveniencia con base en la riqueza y la economía de la mujer (Ibarra, 2011). Sin embargo, cuando vuelve de su escuela en Londres, Enrique vacila entre el amor que podría sentir por Carlota y las lecciones de su padre sobre el matrimonio. Sus dudas sobre la necesidad de la riqueza parecen corresponder con las de Carlota, quien, queriendo librar a Sab y los otros esclavos de sus fincas cuando se case con Enrique, pregunta «iq]ué importa ser menos ricos?» (Gómez, 2008, p. 58).
Sin embargo, cuando Enrique descubre la ruina de la familia Bellavista piensa renunciar a Carlota porque $«[s]$ egún las ideas en que había sido educado, nada era más razonable que la oposición de su padre a un enlace que ya no le convenía...» (Gómez, 2008, p. 133). Eventualmente decide seguir adelante con el matrimonio destinado al fracaso, donde se dedica a los negocios familiares a expensas de su delicada esposa Carlota. Luego, se le remite a Carlota una carta de Sab en la que el difunto ex esclavo de la familia Bellavista proclama su amor puro y duradero por ella. Pero es demasiado tarde. Por cuestiones de raza, clase y avaricia nunca se realizará el amor verdadero y feliz entre los dos.

Pocos textos como Sab critican tan explícitamente la intrusa presencia inglesa en Hispanoamérica (French, 2005). María de Jorge Isaacs es mucho más típica de un texto oblicuo que parece admirar la cultura británica por un lado, pero sutilmente alude a su poder destructivo por otro (French, 2005). Aquí, el amor se prohíbe por la juventud y las responsabilidades familiares de Efraín, tanto como la enfermedad recién descubierta de la bella María. Aunque los jóvenes quieren casarse, la carrera médica de su hijo y la continuación de la fortuna familiar les importa más que nada a los padres de Efraín (French, 2005; Ward, 2002). 
Por eso, mandan al joven a Londres para estudiar y cumplir los sueños de su padre, quien le explica: «Es el estudio uno de tus goces predilectos (...) he concebido grandes esperanzas, por tu carácter y aptitudes, de que coronarás lucidamente la carrera que vas a seguir» (Isaacs, 1982, p. 44).

Efraín ya había pasado seis años en un nuevo colegio distinguido en Bogotá y María se desespera ante otra extendida ausencia de su querido. Antes de que él la abandone otra vez, ella se lamenta,

¿[Q]ué haré? Dime, dime qué debo hacer para que estos años pasen. Tú durante ellos no vas a estar viendo todo esto. Dedicado al estudio, viendo países nuevos, olvidarás muchas cosas horas enteras; y yo nada podré olvidar (...) [m]e dejas aquí, y recordando y esperando voy a morirme (Isaacs, 1982, p. 227).

Pero Efraín, impotente contra los deseos de su padre, únicamente le puede avisar, «no hables así; vas a destruir el último resto de mi valor» (Isaacs, 1982, p. 227). A la enferma María no le queda más remedio que esperarlo impacientemente en Colombia.

Un año después le escribe a Efraín que ya no resiste su triste soledad y los estragos de su enfermedad. El desesperado Efraín sale de Londres para Colombia a verla una vez más antes de que se muera. De prisa al valle, recuerda, «[p]or primera vez después de mi salida de Londres me sentía absolutamente dueño de mi voluntad para acortar la distancia que me separaba de María» (Isaacs, 1982, p. 262). Pero la delicada María muere antes de que Efraín llegue y otro amor termina en tragedia. Después del funeral, el padre de Efraín exclama: "Yo, autor de ese viaje maldecido [de Efraín a Londres], la he muerto» (p. 273).

Al principio de su largo relato, el mismo Efraín lamenta el tiempo que perdió lejos de María en Londres cuando amonesta al lector: «i[L]os que no habéis llorado de felicidad...llorad de desesperación si ha pasado vuestra adolescencia, porque así tampoco volveréis a amar ya!» (Isaacs, 1982, p. 22).

En María los ingleses también penetran las aparentemente inocuas descripciones costumbristas sobre el ocio y el comercio del Valle del Cauca. Carlos, el otro pretendiente de María, orgullosamente le muestra a Efraín su nueva escopeta inglesa para ir de caza. Aunque le anuncia que «nunca había venido al país cosa semejante» (Isaacs, 1982, p. 84), Efraín reconoce que su padre le ha regalado un arma exactamente igual. Entretanto, un irlandés, William Sardick, explota las minas de oro del Chocó con cuadrillas de esclavos ilegales e

36 La amenaza inglesa en la novela hispanoamericana, 1841-1982 Charles B. Moore 
introduce por el río Atrato la mayoría de las mercancías extranjeras que se consumen en el Cauca (Isaacs, 1982). Con su hermano, Thomas, William también gestiona otras «especulaciones bastante lucrativas para [poder] regresar rico a su país, de donde había venido miserable» (p. 185). Para facilitar estos negocios la casa de los Sardick sirve de lugar de tránsito y refugio para otros extranjeros que negocian en Colombia. Uno de ellos es un joven inglés que descansa por casualidad en la casa de los Sardick en su regreso de las Antillas al interior de Nueva Granada antes de empezar la difícil navegación del río Atrato. Esta especulación mina el sustento del valle y enemista a los pequeños empresarios, trabajadores y hacendados honestos que sufren las consecuencias.

\section{Amalia: la amenaza eco-política}

Amalia de Jorge Mármol es un complicado ensayo político-histórico y una novela romántico-realista. Es tanto un cuento de amor entre el héroe Eduardo Belgrano y la bella Amalia como una detallada historia sobre la guerra civil argentina y la cruel dictadura de Juan Manuel de Rosas. A pesar de su género ambiguo, los ingleses presentados allí dentro no vacilan en afectar el futuro de la región rioplatense a su favor. Mármol, para advertirnos sobre la «experiencia» de los ingleses en el sangriento tema a la mano, recuerda al lector, «[e]n la época a que nos referimos, además, la salud del ánimo empezaba a ser quebrantada por el terror: por esa enfermedad terrible del espíritu, conocida y estudiada por la Inglaterra...mucho tiempo antes que la conociéramos en la América» (1955, tomo I, p. 9).

Igual que $S a b$, la aguda crítica anti-inglesa del autor se revela por medio de los personajes (French, 2005; Fernández, 1993). Cuando la novela abre, la policía secreta de Rosas acaba de herir a Eduardo, a quien su amigo y partidario unitario Daniel Bello lleva a la cercana casa del maquiavélico ministro inglés John Henry Mandeville. Pero, curiosamente, los jóvenes ven que el impredecible ministro se divierte en tertulia «[m]ientras a sus puertas se asesina a los ciudadanos de este país» (Mármol, 1955, tomo I, p. 20). Al respecto Daniel explica:

[Y] es precisamente por eso por lo que se divierte. Un ministro inglés no puede ser buen ministro inglés, sino en cuanto represente fielmente a la Inglaterra; y esta noble señora [Inglaterra] baila y canta en derredor de los muertos como las viudas de los hotentotes, con la sola diferencia de que éstas lo hacen de dolor y aquélla de alegría (p. 21).

Por un lado le conviene a Inglaterra colaborar tácitamente con Rosas 
contra los unitarios y franceses que bloquean el Río de la Plata. Pero por otro, temiendo la ambición de Rusia en Europa, Inglaterra no quiere alienar completamente a Francia, aunque el comercio inglés sufre en uno de sus mercados más lucrativos de América del Sur. Un día Mandeville se avasalla al tirano Rosas; al próximo lo afrenta vehementemente sobre sus crímenes. Tales malabarismos diplomáticos que Inglaterra efectuaba en Argentina obviamente irritaban a los unitarios como Eduardo y Daniel, quienes, a su vez, conllevan la amargura y sarcasmo del mismo Mármol.

Mármol, siempre intruso en la narrativa, conjetura que «nacieron las primeras simpatías" (1955, tomo I, p. 109) de Inglaterra por la dictadura cuando Rosas le concedió a Mandeville un tratado sobre la abolición de la esclavitud en Argentina.

Inglaterra ya había invadido a la Banda Oriental en 1807 para crear un Uruguay independiente de Brasil y Argentina, bajo una esfera de influencia inglesa (Winn, 1976). Ahora Inglaterra espera incorporar a Argentina también mientras Francia se distrae cada vez más con sus guerras en Argelia y el Oriente (Mármol, 1955, tomo I). Sin embargo, Inglaterra tiene que andar con pies de plomo con los emigrados argentinos a quienes Rosas acusa «de vender y sacrificar los intereses y los derechos de su país en sus relaciones con el extranjero»(Mármol, 1955, tomo II, p. 94, énfasis del editor Mitre).

Según Mármol, Rosas usa la alianza emigrado-extranjero como su "caballo de batalla» para «estigmatizar a sus contrarios» con "punzantes recriminaciones, de las más infundadas y arbitrarias sospechas» (1995, tomo II, p. 95). Después de interminables peripecias en su lucha contra Rosas, Daniel y Eduardo ven a un nuevo aliado improbable en los oportunistas ingleses y conspiran con Mandeville para gestionar un futuro democrático en Argentina y Uruguay post-Francia y Rosas.

Con un brindis de jerez, Daniel y Eduardo efectúan precoces conversaciones con «respetuosa familiaridad» (Mármol, 1955, tomo II, p. 376) en la sala de la casa del señor Mandeville. Primero Daniel le halaga al inglés con certeza, «yo estoy seguro de que el gobierno británico no sacrificará las simpatías argentinas, ni por hostilizar al gobierno francés ni por corresponder a la reacción que en el Estado Oriental [Uruguay] va a operarse en favor de Inglaterra» (p. 375). Cuando Mandeville disimula, Daniel le explica: «[Q]uiero decir que, abandonadas por la Francia la República Oriental y la numerosa emigración argentina que hay allí (...) es muy probable que

38 La amenaza inglesa en la novela hispanoamericana, 1841-1982 Charles B. Moore 
(...) las simpatías públicas se vuelvan hacia la Inglaterra, que fue tan leal en otra época en sus trabajos por la independencia oriental» (tomo II, pp. 375-376). Mandeville afirma entonces, "-jah, sí, es cierto! La independencia oriental es debida, hasta cierto punto, a los buenos oficios de la Inglaterra» (p. 375).

Daniel entonces continúa presionándolo sobre las intenciones inglesas en Uruguay:

Así es que (...) perdida la influencia francesa en estos países, y llegado el caso en que peligrase la independencia oriental, la acción de la Inglaterra, no sólo sería eficaz, sino también un golpe habilísimo para conquistar a favor suyo todo el terreno perdido por la Francia en países tan llenos de porvenir como los del Plata (p. 376).

Cuando Mandeville sarcásticamente responde que Bello sería «un embajador peligroso para el general Rosas» (1955, tomo II, p. 377), Daniel remarca igualmente, «en esta época no pueden hacer apuntes sino los ministros extranjeros (...) ¡Qué feliz es usted, señor Mandeville! Vivir en esta casa es como estar en Inglaterra»(p. 377). Daniel finalmente clarifica el objetivo de su visita: «-Que estando en Buenos Aires la Inglaterra, y habiendo tantos que caminarían mil leguas por alejarse del país en estos momentos, no hayan caminado algunas cuadras y llegádose a esta casa» (p. 377).

Mandeville trata de darle su palabra de que no hospeda malhechores de Rosas y que sus instrucciones de Londres son de observar «la más completa circunspección» (Mármol, 1955, tomo II, p. 377). Pero Daniel lo interrumpe, "-[p]erdone usted; no quiero saber nada. Si hay algunos desgraciados cubiertos por la bandera inglesa en esta casa, es un deber y una humanidad de parte de usted, señor Mandeville, y yo no cometería la indiscreción de querer saberlo» ( $\mathrm{p}$. 377). Además, Daniel le advierte que en estos momentos de «efervescencia popular» la seguridad de cualquier refugiado no se garantiza y que Mandeville bien quisiera «evitar los conflictos diplomáticos que necesariamente tendrían lugar, si el pueblo olvidase los respetos de la Legación» (p. 377). Mandeville le promete que ya les ha negado el asilo a algunos (supuestamente rosistas) que se lo han pedido porque los ingleses no quieren «traer más conflictos a este país, por cuyos habitantes tengo las más profunda simpatía y con el cual mi gobierno se esmera en mantener las más estrechas relaciones de amistad» (p. 378.).

Sin embargo, a pesar de los esfuerzos diplomáticas entre los ingleses, franceses y argentinos, Daniel y Eduardo 
eventualmente mueren a manos de los bandidos de Rosas. Igual que Carlota en Sab, Amalia queda sola al final. En 1852 las tropas del general Justo José de Urquiza, apoyadas por Brasil, Uruguay y la provincia argentina de Corrientes, derrocan a Rosas, quien primero se refugia en la legación inglesa en Buenos Aires y poco después se exilia en Inglaterra donde muere en 1877 (Fernández, 1993).

\section{Cecilia Valdés: la amenaza abolicionista}

A comienzos del siglo XIX los poderes colonialistas europeos empezaron serias tentativas de acabar con la institución de la esclavitud en América. En 1817, Gran Bretaña y España firmaron un tratado que prohibía el comercio de esclavos del África. Aunque el acuerdo permitía que las naves británicas inspeccionaran cargamentos sospechosos, otras rendijas minaban el tratado y el tráfico de esclavos volvió a fluir fuertemente a Cuba. Bajo los términos del convenio Inglaterra le pagó a España para que cesara la esclavitud en Cuba, Puerto Rico y la República Dominicana. Eventualmente, los esclavos se declararon libres en 1870 y la esclavitud se abolió en Cuba en 1886 (Sáinz de Medrano, 1993).

En Cecilia Valdés de Cirilo Villaverde la presencia de los ingleses «amenaza» con interrumpir para bien la trata de esclavos en Cuba. Es, así, una presión más sobre las tenues vidas de los principales personajes de la novela. Leonardo, hijo de un rico hacendado español, Cándido Gamboa, se enamora de una bella mulata de aspecto blanco, Cecilia, sin saber que es su media hermana paterna. El padre Gamboa se opone a la relación y encierra a Cecilia en un convento. Cuando nace un niño ilegítimo Leonardo se aleja de Cecilia para casarse con Isabel, una joven de su propia clase. Para vengarse Cecilia convence a otro pretendiente suyo, Pimienta, de que mate a Leonardo.

El padre Gamboa es «representante conspicuo de la alta burguesía cubana, y de sus allegados» (Sáinz de Medrano, 1993, p. 145). Rodeadas por otras largas viñetas costumbristas y sentimentales, destacan varias conversaciones entre Gamboa y sus socios y entre Leonardo y su madre doña Rosa de Gamboa, que exponen la gestión de la trata, la mentalidad criolla que la apoya y la estrategia inglesa en contra de ambas. En todas, el espíritu abolicionista de Villaverde sale a plena vista.

La ingenua doña Rosa nunca parece haber pensado en los horrores de la esclavitud que han mantenido la riqueza de su familia. Le explica a Leonardo que el lujo en que viven proviene del taller

40 La amenaza inglesa en la novela hispanoamericana, 1841-1982 Charles B. Moore 
de maderas, el terreno, el barracón y el ingenio de su familia donde todavía se encuentran algunos esclavos. Sin embargo, le advierte, los ingleses persiguen tanto la trata de esclavos de África del padre de Leonardo y sus socios que «se pierden muchas más expediciones que se salvan» (Villaverde, 1986, p. 64) y hay demandas contra la trata por la «maldita comisión mixta» (p. 99). Por eso, el padre de Leonardo se junta con otros hacendados para conspirar contra los ingleses y procurar que los próximos barcos de esclavos desde África no desembarquen por los alrededores de La Habana. Que sepa ella, el bergantín Veloz, que lleva un «buen cargamento» de esclavos (Villaverde, 1986, p. 99), ya está perseguido por un buque inglés. Ella resiente esta interferencia porque «[c]on todo, esos ingleses protestantes se figuran que el mundo entero les pertenece» (p. 99). Le advierte a su hijo que por los altos costos de la trata su esposo ya trabaja «en sociedad con sus amigos» (p. 99) y que la familia puede perder mucho si se pierde la actual expedición de quinientos negros.

Sin embargo, el joven Leonardo sigue confundido sobre la continua ausencia de su padre. Por eso, su madre le cuestiona en forma emocional, «-iAy! hijo, ¿echarías tú tanto lujo, ni gozarías de tantas comodidades, si tu padre dejase de trabajar? Las tablas y las tejas no hacían rico a nadie. ¿Qué negocio deja más ganancias que el de la trata?» (Villaverde, 1986, p. 99). Después, enfatizando el tema anti-inglés, ella lo desafía:

[D]í tú que si los egoístas ingleses no dieran en perseguirla, como la persiguen en el día, por pura maldad, se entiende, pues ellos tienen muy pocos esclavos y cada vez tendrán menos, no había negocio mejor ni más bonito en que emprender (pp. 99-100).

Cuando llega el bergantín al puerto indicado los socios de Gamboa no pueden fijar el número de esclavos abordo. Uno explica que «aunque embarcó [desde África] sobre 500, con el largo viaje y la atroz caza que le han dado los ingleses, se le han muerto algunos y tenido que echar al agua ... muchos» (Villaverde, 1986, p. 106). Se enfurece Gamboa quejándose con doña Rosa: «Si seguimos como vamos todavía los pícaros de los ingleses han de causar la ruina de este hermoso florón de S. M. el rey, que Dios guarde» (p. 106). Rosa está atónita por el peligro en que están y Gamboa le repite, «[c]omo lo oyes, porque si los ingleses no nos dejan importar los brazos que nos hacen falta, no sé con qué ni cómo vamos a elaborar el azúcar» (p. 106). Su esposo también le dice que el inglés Lord Paget ha apresado el bergantín Veloz con casi todo el cargamento de esclavos abordo. 
Sin embargo, Gamboa espera que sus socios puedan «arrancarlos de las garras de los ingleses» (p. 106). Doña Rosa no puede animar mucho a su esposo cuando, con una buena dosis de racismo, razona:

-¡Ah! Cándido, no te hagas ilusiones. Tú y tus amigos abrigan esperanzas, yo no. Cuando los ingleses agarran, no sueltan, tenlo por seguro. Cada vez me parecen más odiosos esos judíos protestantes. Vea usted, ¿quién los mete en lo que no les va ni les viene? Yo me hago los sesos agua, y no atino a comprender porqué [sic] se ha de oponer Inglaterra a que nosotros traigamos salvajes de Guinea. ¿Por qué no se oponen también a que se traiga de España aceite, pasas y vinos? Pues hallo más humanitario traer salvajes para convertirles en cristianos y hombres, que vinos y esas cosas que sólo sirven para satisfacer la gula y los vicios (Villaverde, 1986, p. 107).

Gamboa rápidamente responde, «Rosa, los enemigos de nuestra prosperidad, quiero decir, los ingleses, no entienden esa filosofía» (Villaverde, 1986, p. 107). Pero a quien Gamboa culpa más que a los ingleses es al rey don Fernando VII de España, quien aceptó las 500.000 libras inglesas en el tratado de 1817. Así el monarca les concedió «el derecho de visita de nuestros buques mercantes y de insultar (...) el sagrado pabellón de la que no ha mucho fue señora de los mares y dueña de dos mundos [España]» (p. 107). Con desesperación concluye, «iqqué vergüenza! No s[é] cómo toleramos [más] al caso, Rosa» (p. 107).

En este momento, Rosa empieza a arrepentirse cuando oye que algunos negros se echaron al mar o murieron sofocados abordo del Veloz. Cándido niega su compasión con «el más exquisito desprecio» y «brusquedad» (Villaverde, 1986, p. 109), mientras le recuerda la persecución «arbitraria»de los «testarudos» $\mathrm{y}$ "perros ingleses» (p. 112). Para él, cuando el mundo acepte que los negros no sean hombres con alma y que no sean nada más que animales, sacos de carbón o bultos de tabaco, «entonces se acabará uno de los motivos que alegan los ingleses para perseguir la trata de África» (p. 109).

Los socios de Gamboa reconocen la gravedad de la situación y hablan con el representante del capitán general de Cuba, el doctor Francisco Dionisio Vives, dueño de hasta dos docenas de gallos de riña ingleses. Para rescatar su valioso cargamento de esclavos Cándido le miente a Vives diciéndole que el Veloz no era negrero de Guinea, sino un bergantín de Puerto Rico con ladinos, lo cual sí se permite por el tratado de 1817 con Inglaterra. A Vives le preocupa «el celo exagerado de los ingleses» (Villaverde, 1986, p. 119) porque también le faltan esclavos para su

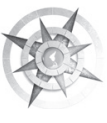


mismo cafetal de aguacate. Gamboa le responde: «-i[y] a quién no le hacen falta? Eso es lo que todos los hacendados necesitamos, como el pan. Sin brazos se arruinan nuestros ingenios y cafetales. Y tal parece que es lo que buscan esos judíos ingleses que Dios confunda» (Villaverde, 1986, p. 119).

Gamboa soborna a Vives con un buen número de esclavos si le puede liberar el Veloz de los ingleses, quienes, cree, piensan destruir la riqueza agrícola de la isla. Vives les promete que también quiere castigar a los ingleses y que ya está en contacto con el cónsul inglés y el capitán del Veloz Clarence Paget. Sin embargo, al final de la reunión les advierte:

-Reconozco, señores, la injusticia y los daños que nos ocasiona un tratado por el cual se concede a Inglaterra, la enemiga natural de nuestras colonias, el derecho de visita sobre nuestros buques mercantes; pero los ministros de $\mathrm{S}$. M., en su alta sabiduría, tuvieron a bien aprobarlo, y a nosotros, leales súbditos sólo nos toca acatar y obedecer el mandato del augusto monarca Q. D. G (...) no se metan en las garras de los ingleses y salvará sus expediciones, ni comprometan la honra del Capitán General. La prudencia es la primera de las virtudes en el mundo (Villaverde, 1986, pp. 122-123).
Con sus mandatos «no se metan» $\mathrm{y}$ «ni comprometan»; Vives expone su miedo ante el poder inglés y las limitaciones militares y diplomáticas del Gobierno español de Cuba. Los mejores consejos realistas que les puede ofrecer es que obedezcan la ley, y si no que tengan cuidado en lo que hagan en su contra.

\section{El inglés de los güesos: la amenaza económica metafórica}

La mayor parte de la producción literaria de Benito Lynch se preocupa de cuadros realistas sobre la psicología de los habitantes del campo y de la pampa (Head, 1971). A principios del siglo XX los cambios e innovaciones de la industrialización mundial amenazaban estas antiguas tradiciones y costumbres rurales. Un símbolo de esta problemática en Lynch es la curiosa, si no siniestra y amenazante, figura del extranjero. A pesar de su diligencia y ambición, este intruso ignora la vida campesina y es incapaz de adaptarse al ambiente del «tosco paisano bonaerense» (Head, 1971, p. 92). A su vez los paisanos llegan a resentirse con él, si no a odiarlo, lo cual muchas veces conduce a violentos choques.

En El inglés de los güesos el extranjero es un profesor universitario inglés, míster James, quien llega a la pampa argentina para hacer investigaciones 
antropológicas en los cementerios indígenas de la estancia La Estaca. Al principio, el excéntrico James es un tipo popular, quien les da tema de conversación a todos los granjeros y trabajadores del área. Una de las primeras personas con quien James establece «cordiales relaciones» (Lynch, 2004, p. 39) es la niña de la familia de La Estaca, Balbina, también conocida como La Negra. A él le atraen la belleza, juventud y alegría de la joven, y a ella le interesaban vivamente la rareza, sabiduría, sonrisa y personalidad de James.

En una serie de escenas iniciales, sin embargo, los implacables campesinos se burlan sin piedad de las costumbres de su visitante inglés. El burlador más serio es el pretendiente rechazado y resentido de Balbina, Santos Telmo, quien piensa reconquistar a su querida. Pero la monstruosa araña que Telmo pone en una jarra de agua no solamente no asusta al estudioso James, sino que le fascina como un «ejemplar rarísimo de Argiopo argentata» (Lynch, 2004, p. 41). Para vengarse, Santos engaña a la ingenua Balbina para que ella le sirva a James una bombilla de mate caldeada para quemarle los labios. La enfurecida madre de La Negra, Doña Casiana, abofetea a su hija delante de todos los invitados de la cena.

Balbina está humillada públicamente. Odia a James y piensa vengarse contra sus «ridiculeces $[y]$ crasa ignorancia»
(Lynch, 2004, p. 45). Cuando se niega a servirle tortas su madre le pega otra vez. Pero poco después, cosa extraña, Balbina rechaza a Santos de una vez por todas. El confundido Santos acude a su chismoso amigo Deolindo, quien le comenta la relación que sospecha entre Balbina y el «diantre» inglés (p. 62). El furioso Santos entonces conspira otro complot para destruir la tarea de su rival y finalmente volver a conquistar a Balbina. Lynch entonces se detiene largamente para desarrollar la tensión sentimental de lo que será una relación confusa y desconcertante entre James y La Negra.

La ingenua Balbina entiende mal los inocentes actos del afable, si no siempre pragmático, inglés. Cuando ella de repente se enferma gravemente de los oídos, él no vacila en tratarla con la «maravillosa ciencia médica» de su botiquín de campo (Lynch, 2004, p. 78) que suple "la torpe medicina casera" de la pampa (p. 82). Incluso hace quehaceres para facilitar su recuperación. Un día Balbina se da cuenta de que está hablando amistosamente con un hombre a quien, hace poco, ella consideraba únicamente un «mocetón raro» (Lynch, 2004, p. 87). Así empieza la extraña e inesperada obsesión de la campesina con su visitante inglés.

Otro día Balbina decide entrar a hurtadillas a la alcoba de James. Al hurgar con cautela un baúl de sus 44 La amenaza inglesa en la novela hispanoamericana, 1841-1982
Charles B. Moore

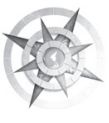


pertenencias personales, empieza a besar y acariciar furtivamente una foto de él. Pero su trance se interrumpe súbitamente cuando los rancheros arrastran a la casa a James gravemente herido por una apuñalada de Santos. Balbina se dedica a cuidarlo hasta que se reponga y cree que su extendido tiempo juntos por fin romperá la terca distancia emocional que los ha separado hasta ahora. James, sin saberlo, la seduce con inocentes relatos de su vida personal y cultural en Inglaterra. Ya ejerce una atracción irresistible sobre la niña, cuyo amor por él ya se ha convertido en un «aroma violento [que] embriaga los sentidos» (Lynch, 2004, p. 135).

Lynch informa al lector que falta algo. La delicada Balbina nunca puede penetrar del todo al misterioso, enigmático y hermético míster James. Un día Balbina se entera de que su querido James es casado. A pesar de las súplicas, lágrimas e incluso el curanderismo de una amiga de Balbina, James decide volver a la segura vida académica que conoce en Inglaterra. Igual que Carlota, Efraín, Amalia y Cecilia, ahora Balbina está devastada indirecta o directamente por los ingleses. La novela concluye con su suicidio.

Aunque James puede amar a La $\mathrm{Ne}$ gra, nunca se permite a sí mismo corresponder a su amor. Su prioridad es siempre su labor profesional. A través del profesor inglés, Lynch destaca metafóricamente las diferencias irreconciliables entre la explotadora cultura inglesa y la explotada pampa argentina. Así, Lynch nos comunica su visión pesimista del mundo, donde lo espiritual tradicional es vencido por la frialdad conceptual del mundo moderno occidental representado por el míster James (Torres de Peralta, 1976). A diferencia del costumbrismo idealizado de los románticos argentinos como Güiraldes, Hidalgo o Hernández, Lynch sí elige criticar abiertamente la explotación británica de la pampa argentina (French, 2005). Con realismo incorpora los efectos negativos de las inversiones británicas en su país y cuestiona la tradicional ideología capitalista difundida por los escritos de viajes de Darwin u otros (French, 2005). El inglés de los güesos, tanto como El romance de un gaucho (1930), son versiones excéntricas de la novela gauchesca tradicional que exponen la pobreza rural frente a la prosperidad moderna (French, 2005). La conquista «casual» del erudito aventurero inglés James, modelado sobre el mismo Darwin, es un símbolo de este proceso (Gates, 1961; French, 2005).

\section{La guerra del fin del mundo (1981): la amenaza invisible}

Los novelistas del boom recogen el tema de la presencia y amenaza 
inglesas a través de la historia de Hispanoamérica. Gabriel García Márquez escribe en Cien años de soledad (1967):

[C]uando el pirata Francis Drake asaltó a Riohacha, en el siglo XVI, la bisabuela de Úrsula Iguarán se asustó tanto (...) que (...) se sentó en un fogón encendido (...) [y] soñaba que los ingleses con sus feroces perros de asalto se metían por la ventana del dormitorio (...) maldecía la hora en que Francis Drake asaltó a Riohacha (Márquez, 1992, p. 24).

Además de la piratería, los ingleses jugaban también a la política. En El arpa y la sombra (1979) Alejo Carpentier explica que durante las guerras de independencia de las colonias españolas los ingleses hospedaron en Londres comisiones y logias de jóvenes patriotas que se especializaban «en promover agitaciones políticas en el mundo hispánico» (Carpentier, 1999, pp. 27-28).

Otras veces los ingleses combinaron la política con los negocios. Al respecto Carpentier escribe en El reino de este mundo (1949): «[D]esde los trágicos días de la ejecución del Delfín Víctor, desde la salida de Port-auPrince, propiciada por comerciantes ingleses, antiguos proveedores de la familia real, las princesas conocían, por vez primera en Europa, un verano que les supiera a verano» (2013, p. 107). Sana y salva de la rebelión negra gracias a los ingleses, la familia real francesa disfrutaba de hierbas homeopáticas provenientes del Cabo vía Londres. Entretanto, entre las ruinas de la lujosa mansión Sans-Souci de Henri Christophe en Haití el anciano ex esclavo, Ti Noel, encuentra «[u]n pez embalsamado, regalo de la Real Sociedad Científica de Londres al príncipe Víctor» (2013, pp. 112-113).

La explotación de las comunidades indígenas por los oportunistas extranjeros es el principal tema de La casa verde (1965), donde Vargas Llosa comenta los engaños, los líos y la catástrofe económica que trajeron «los que venían de afuera» (Vargas, 1999, p. 203). Un ejemplo es cuando un gobernador de la región cauchera del Perú explica a su amigo militar:

[L]a vez pasada habían sido unos extranjeros, unos ingleses, con el cuento de la botánica; se habían metido al monte y se llevaron semillas del árbol del caucho y un día el mundo se llenó de jebe salido de las colonias inglesas, más barato que el peruano y el brasileño, ésa había sido la ruina de la Amazonía...» (Vargas, 1999, p. 203).

En La guerra del fin del mundo (1981) el Brasil de 1890 acaba de establecerse como república después de una larga época colonial bajo el Imperio portugués. Una secta de fanáticos beatos

46 La amenaza inglesa en la novela hispanoamericana, 1841-1982 Charles B. Moore 
religiosos (conocidos como los yagunzos) pronto lleva a cabo una sangrienta insurrección popular en la provincia de Bahía en un aislado rincón al fin del mundo, en el extremo noreste del país. Un llamado consejero ejerce un extraño embrujamiento mágico sobre sus seguidores, quienes han establecido un asentamiento utópico nombrado Canudos. Dentro de la historia de esta rebelión mueven otros intereses que complican la trama de la novela.

Para los rebeldes yagunzos la única manera de rescatar a Brasil de las corruptas garras de la nueva república secular es el restablecimiento del vencido Imperio portugués-católico. Aunque al principio las viejas élites hacendadas toleran a los yagunzos, están en contra de cualquier amenaza a su poder económico y político, que ejercen sobre Bahía por medio de sus grandes extensiones de tierras feudales. El oportunista Partido Republicano Progresista, aprovechándose de la debilidad de la joven república en Bahía, conspira para derrocar lo que llaman la dictadura monárquica de los terratenientes retrógrados, que bloquea la modernización de la provincia. La única razón por la cual los progresistas apoyan cualquier triunfo de los fanáticos yagunzos de Canudos es para provocar una intervención federal que acabe también con el feudo de los barones que empobrece la región.
En el constante vaivén ya a favor, luego en contra de la república, los progresistas, el militar, la secta religiosa y los hacendados, todos se posicionan para obtener despojos de la rebelión. Entretanto, hay continuas batallas contra los anónimos e invisibles ingleses cuyo supuesto apoyo para la guerrilla yagunza en contra de la república siempre se sospecha, pero nunca se comprueba a ciencia cierta.

El disolvente y vagabundo escocés Galileo Gall inmigra a Brasil para promover su frenología de anarquismo internacional después de una vida «de aventuras, cárceles, golpes de mano, reuniones clandestinas, fugas [y] reveses» (Vargas, 1991, p. 27) en Europa, Turquía y Estados Unidos. Conoce al jefe del Partido Progresista Epaminondas Gonçales, quien lo contrata supuestamente para correr armas a los yagunzos. Gonçales, sin embargo, luego ordena que sus fuerzas maten a Gall para mostrar que en realidad hay ingleses en Bahía que encienden a los yagunzos contra los hacendados y la república. Pero cuando Gall apenas sobrevive al ataque descubre que era solamente el cadáver inglés que los progresistas buscaban para plantar fusiles de Liverpool en la región. Ya quiere luchar para los yagunzos más que nunca, porque: «[S] oy escocés y odio a los ingleses» (Vargas, 1991: p. 124). 
Cuando la expedición militar republicana del mayor Brito fracasa contra los yagunzos, se publica un artículo en el periódico local progresista sobre el sangriento descubrimiento del "cadáver del agente inglés» (Vargas, 1991: p. 139). Armados con estas falsedades los progresistas acusan formalmente al Gobierno de Bahía y a los hacendados «de haber atizado y armado la rebelión de Canudos, con ayuda de Inglaterra a fin de producir la caída de la República y la restauración de la monarquía» (p. 140).

Los progresistas se quejan:

A pesar (...) del descubrimiento de un cargamento de fusiles ingleses destinado a Canudos, y del cadáver del agente inglés Galileo Gall (...) las autoridades del Estado (...) han mostrado una pasividad y abulia sospechosas, al no haber solicitado en el acto, como lo reclaman los patriotas de $\mathrm{Ba}$ hía, la intervención del Ejército Federal para aplastar esta conjura que amenaza la esencia misma de la nacionalidad brasileña (p. 140).

Los otros partidos sospechan el engaño progresista y amenazan con abandonar la sesión del parlamento si siguen las deliberaciones sobre la rebelión restauradora de Canudos y la intervención de la Corona británica en los asuntos brasileños. Los progresistas insisten en que tienen testigos que comprueban que Gall era espía inglés. Los delegados creen que el Gobierno republicano todavía puede ganar aunque la rebelión tenga este apoyo.

El Gobierno nacional en Río entonces envía al Ejército a Bahía para luchar contra Canudos bajo el liderazgo del héroe nacional, el coronel Moreira César, quien proclama:

El séptimo Regimiento está aquí para debelar una conspiración monárquica. Porque detrás de los ladrones y los fanáticos de Canudos hay una conjura contra la República. Esos pobres diablos son un instrumento de los aristócratas que no se resignan a la pérdida de sus privilegios, que no quieren que el Brasil sea un país moderno. De ciertos curas fanáticos que no se resignan a la separación de la Iglesia del Estado porque no quieren dar al César lo que corresponde al César. Y hasta de la propia Inglaterra, por lo visto, que quiere restaurar ese Imperio corrompido que le permitía apropiarse de todo el azúcar brasileño a precios irrisorios. Pero están engañados. Ni los aristócratas, ni los curas, ni Inglaterra, volverán a dictar la ley en el Brasil. El Ejército no lo permitirá (Vargas, 1991: p. 157).

Pero cuando las fuerzas de César y las del general Febronio de Brito pierden, el militar, los barones y los progresistas descubren que la derrota de los

48 La amenaza inglesa en la novela hispanoamericana, 1841-1982 Charles B. Moore 
yagunzos no será fácil. Las tres partes no se dan cuenta de que deberían unirse contra los rebeldes para sobrevivir. En una junta, los hacendados afirman:

El Mayor Febronio no es tan inepto como quiere hacernos creer. Su derrota ha sido deliberada, negociada, decidida de antemano [por la República de Río de Janeiro], a través de Epaminondas Gonçalves [jefe de los progresistas]. Para tener ese escándalo nacional que buscan desde que [la monarquía imperial] dejó el poder. ¿No han estado inventando conspiraciones monárquicas desde entonces para que el Ejército clausure el Congreso e instale la Republica Dictatorial? (...) No hay hechos, solo las fantasías y las intrigas más increíbles (...) Nos acusan de azuzar a los [yagunzos], de envirarles armas, de estar conspirando con Inglaterra para restaurar el Imperio (Vargas, 1991: pp. 175-176).

Los hacendados dicen que van a seguir en el poder al colaborar con su enemigo anterior, el Ejército de la república: «Somos nosotros, junto con Moreira César, quienes acabaremos con los conspiradores monárquicos financiados por la Reina Victoria (...) y cuando el coronel acabe con los pobres [yagunzos] celebraremos con grandes fiestas la derrota del Imperio Británico y de los Braganza» (Vargas, 1991: p. 179).
Pero el militar desconfía de la lealtad del barón de Cañabrava y su coetáneo hacendado. El coronel César dice que Cañabrava «opta por el patriotismo, para que los republicanos no lo desplacen. Distraer y confundir por ahora para intentar después otro zarpazo. El Barón tiene buena escuela: La escuela inglesa, señores» (Vargas, 1991: p. 184). Los barones responden, «[n]o podemos dejar que el Brasil nos crea alzados contra la República, y hasta complotando con Inglaterra para restaurar la monarquía» (p. 199). Pero César dice, «[o]dio a los terratenientes locales y a los mercaderes ingleses que han mantenido esta región en la prehistoria (...) Odio a quienes el azúcar les interesaba más que la gente del Brasil» (p. 224). Aunque los rumores afirman que el barón de Cañabrava fue a Inglaterra a gestionar la rebelión y dio a los rebeldes parte de su hacienda para construir su colonia utópica Canudos, César todavía insiste, «[e] sos ladrones reciben ayuda de agentes ingleses. ¿Quién si no los monárquicos puede fomentar una insurrección contra la Republica?» (p. 225).

Cuando César muere y el militar pierde todavía otra batalla contra los yagunzos, los barones y progresistas finalmente hacen las paces para unirse contra su enemigo común en Canudos. Incluso el Barón está convencido de que los ingleses están ayudando a 
los yagunzos. Sus colegas hacendados y él ya sospechaban tal posibilidad mucho antes en otra reunión estratégica cuando «ardían de impaciencia por conocer los detalles de [la] victoria [de la república] contra los que el Coronel [César] quería hacer pasar por restauradores y agentes de Inglaterra» (Vargas, 1991: p. 289). En ese momento Cañabrava ponderaba, «[e]sta tierra se me ha vuelto extranjera. Estas gentes no son las que he tratado siempre. Quizás el escocés anarquista las entienda mejor. O el Consejero» (p. 289). Ya que los yagunzos queman su tierra, le roban y comen sus animales, son el principal enemigo de los barones y los progresistas.

En la última batalla contra los yagunzos, los soldados gritan «imuera Inglaterra!» (Vargas, 1991, p. 403), mientras un sargento sigue pensando que quiere sacar «a bayoneta y sable a los ingleses de los escondrijos desde donde raleaban a los patriotas» (p. 414). No entiende la guerrilla de los yagunzos, ni qué armas tienen ni quiénes son. El narrador dice, «gracias a estos bandidos ingleses está viendo cosas extrañas, como retirarse de una pelea ya ganada y fajarse a oscuras confiando que Dios orientará las balas contra los invasores» (p. 418).

El Miope, un corresponsal periodístico que reportó la guerra en el terreno y que ahora reflexiona sobre los acontecimientos de la guerra con el barón de Cañabrava, dice que los otros corresponsales que reportaban la guerra no creían que mintieran porque «[p]odían ver pero sin embargo no veían. Solo vieron lo que fueron a ver. Aunque no estuviese allí. No eran uno, dos. Todos encontraron pruebas flagrantes de la conspiración monárquico-británica. ¿Cuál es la explicación?» (Vargas, 1991: p. 422). El barón contesta:

La credulidad de la gente, su apetito de fantasía, de ilusión (...) Había que explicar de alguna manera esa cosa inconcebible: que bandas de campesinos y de vagabundos derrotaran a tres expediciones del Ejército, que resistieran meses a las Fuerzas Armadas del país. La conspiración era una necesidad: por eso la inventaron y la creyeron (p. 422).

El Miope le dice al barón que cuando el médico militar entró a Canudos al final de la guerra con los soldados «[t]odo se le [volvió] confuso. Él esperaba encontrar, aquí, oficiales ingleses, asesorando a los yagunzos, enseñándoles a manejar el armamento modernísimo metido de contrabando por las costas bahianas que se ha descubierto» (Vargas, 1991: p. 457). En cambio, entre los gusanos, las moscas y la sangre de los beatos vio solo dardos y flechas. Inglaterra

50 La amenaza inglesa en la novela hispanoamericana, 1841-1982 Charles B. Moore 
era el chivo espiratorio de la guerra. Igual que el cadáver falso de pelo rubio irlandés que la republica desfiló por los pasillos del capitolio en Río, los periodistas inventaron rubios en plena batalla. Así, Vargas Llosa cuestiona la historia y el reportaje de la misma. Como Sarmiento advierte en Facundo, el desierto y tierra al fin del mundo producen cualquier invento de la imaginación.

\section{La casa de los espíritus (1982): La deconstrucción de la amenaza}

El arpa y la sombra de Carpentier (1979) señala una presencia inglesa ya bien atrincherada en Chile durante la época independentista en 1800. En una parada en Valparaíso, la fracasada misión apostólica del joven canónigo Mastaï se encuentra «en el regazo de un circo de montañas donde tanto se hablaba el inglés como el español, por haber allí prósperos almacenes británicos que comerciaban con las naves fondeadas tras de largas y difíciles navegaciones por el Pacífico meridional» (Carpentier, 1999, p. 45).

La casa de los espíritus tiene lugar un siglo después en un país anónimo que simboliza el mismo Chile, donde los protagonistas de Isabel Allende precariamente siguen aferrándose a una agotada infraestructura de transporte, comunicaciones, turismo y educación ingleses. Este subyacente control extranjero va usurpando sus vidas y muchas veces provoca la tragedia y la muerte a través de la novela.

En el primer capítulo Marcos, el tío aventurero de Clara, muere en un barco inglés durante uno de sus famosos viajes exóticos alrededor del mundo. El furioso capitán inglés Longfellow piensa lanzar su cuerpo al mar, pero lo deja en el puerto cuando no se reclama. Los telegramas del capitán al respecto supuestamente se perdieron en «el correo de esas latitudes [que] no tenía la misma confiabilidad que en su lejana Inglaterra» (Allende, 1982, p. 25).

Poco después aprendemos que el padre Trueba arruina la fortuna familiar. Su hijo, Esteban, el futuro patriarca de la novela y esposo de Clara, hija de Severo del Valle, viaja al Valle Central para investigar la finca de su padre en un vagón de tren tapizado en terciopelo rojo. Su latente latifundismo conservador lo lleva a elogiar «la iniciativa de los ingleses de construir coches de primera clase» (Allende, 1982, p. 51). Después de restaurar la estancia, Esteban inexplicablemente se vuelve cada vez más anglófilo e incluso se cambia de ropa a la hora de cenar, como, decía él, «hacían los colonos ingleses en las más lejanas aldeas del Asia y del África, para no perder la dignidad y el señorío» (p. 60). Cuando su madre 
muere, Esteban vuelve a la capital otra vez en un coche de primera clase «de los tiempos de la compañía inglesa de ferrocarriles» (p. 75). Un terremoto eventualmente destruye la estancia de Las Tres Marías y dos braceros, Pedro Tercero y Esteban García, se vengarán repetidamente de los abusos del oligarca Esteban Trueba.

Severo del Valle retira a su hija Clara de una escuela de monjas debido a una institutriz inglesa a la que no le gusta el clima del país y vuelve a Liverpool. Años después Esteban Trueba, cuando vuelve de Las Tres Marías a la capital para casarse con Clara, admira la estación de trenes que los ingleses habían construido al estilo de la Estación de Victoria «en los tiempos de que tenían la concesión de los ferrocarriles nacionales» (Allende, 1982, p. 85). Le parece que nada ha cambiado desde esa época y que hasta los cargadores de maletas todavía llevan gorras oscuras con la insignia de la corona británica. Luego Nivea, la madre de Clara, busca ropa de París y Londres para su primer viaje a Las Tres Marías con Clara, mientras Esteban recarga la mansión de la estancia con los últimos estilos y productos europeos, como los muebles y el bronce ingleses.

Después de su matrimonio Clara les pone nombres extranjeros a sus hijos y para escapar de su miserable vida con
Esteban se mete en la clarividencia y el trabajo político. El furioso Esteban acude al burdel del hotel Colón en la capital, que florece "pero no había adquirido aún el prestigio internacional que llegó a tener cuando aparecía en las cartas de navegación de las compañías inglesas y en las guías turísticas, y lo filmaron para la televisión" (Allende, 1982, p. 114). Cuando el auto llega al país por primera vez, Severo y Nívea compran un elegante Sunbeam británico con cortinas de encaje y floreros de cristal, pero con malos frenos. La piedra que usan como freno luego los mata en un horrible accidente.

Esteban interna a sus hijos, Jaime y Nicolás, en una rígida escuela inglesa victoriana para protegerlos de la magia y las excentricidades de su madre Clara. Allá les dan varillazos por cualquier pretexto, especialmente a Jaime, quien se burlaba de la familia real británica. Esteban luego observa la conducta salvaje de sus hijos, y años después $\mathrm{Ni}$ colás se hace revolucionario contra la dictadura conservadora inicialmente apoyada por su padre. Irónicamente, el colegio inglés es el único edificio que no se destruye en el catastrófico terremoto que azota al país. Allí siguen jugando al cricket, cantando en inglés y siguiendo las noticias que les llegan con tres semanas de atraso desde Inglaterra. Los estudiantes adquieren un acento de Oxford.

52 La amenaza inglesa en la novela hispanoamericana, 1841-1982 Charles B. Moore 
Esteban ordena platos ingleses pintados a mano para reparar Las Tres Marías después del terremoto. También inicia un negocio de chinchillas con un culto conde francés, Jean de Satigny, que llega súbitamente a la estancia y lleva trajes ingleses de montar a caballo. Esteban arregla que su hija Blanca se case con Jean para alejarla de su amante rebelde Pedro Tercero, el enemigo de Esteban. La extraña pareja toma un barco transatlántico inglés de la capital a su nueva estancia lujosa al norte del país. Blanca pronto descubre que Jean trafica con artefactos indígenas y trabaja como cafiche de pornografía para los sirvientes de la casa. Una noche la horrorizada Blanca escapa de la hacienda rumbo a la capital. Esta fuga de Blanca parece señalar que los otros protagonistas (¿chilenos?) finalmente pueden empezar a resistir el sutil control inglés que los ha dominado implícitamente por tantos años.

Asimismo, Clara escribe a las embajadas de las potencias angloparlantes y el Ministerio de Educación de su país para decirles que a los extraterrestres con quienes ella se comunica no les interesan el inglés ni el francés, sino el esperanto o el español.

Blanca retira a su hija Alba del colegio inglés para señoritas que supuestamente era la mejor educación y apoya la revolución popular. Y en un momento culminante de la novela Blanca curiosamente descubre que el único retrato de su ya difunta abuela Clara se encuentra en un museo de Londres. Está allá con otras obras de arte y mobiliario que Alba le ha vendido al cónsul inglés para refugiar a los perseguidos políticos de la revolución en la casa de Esteban contra la despiadada dictadura derechista.

Al comprarle estos artículos a Alba irónicamente Inglaterra ayuda a una causa que piensa derrumbar la sociedad y economía latifundistas que ella misma ha construido cuidadosamente durante casi doscientos años. Así, Allende propone una alteración radical de la sociedad y una reconciliación de fuerzas opositoras que desafían la fuerza cíclica de la historia (Mandrell, 1990). La novela combina la historia y la invención en un espacio nuevo donde existe la posibilidad de cambios reales, un mundo diferente y una revisión total de las tradiciones aceptadas (Mandrell, 1990).

María, La casa de los espíritus y El inglés de los güesos muestran indirectamente los insidiosos efectos de los ingleses. Sab, Amalia y Cecilia Valdés los critican hostilmente. La cubana Carlota vive rica, pero ignorada por el trabajador Enrique. La colombiana María muere antes de que Efraín regrese de Londres y el míster James provoca el 
suicidio de la desesperada campesina argentina Balbina. Un rival celoso mata a Leonardo, cuyo padre conspira contra los ingleses, y los secuaces de Rosas alineados con Londres asesinan a Eduardo y Daniel. Al anglófilo Esteban Trueba se le mueren, torturan o exilian a casi todos los miembros de su familia. En Sab y El inglés de los güesos los hombres ingleses van a Cuba y Argentina, mientras en Sab y María un joven cubano y uno colombiano, respectivamente, van a Inglaterra. En Maria los ingleses comercian por el río Atrato de Colombia; en Amalia conspiran contra el bloqueo francés del Río de la Plata en Argentina y en Cecilia Valdés patrullan el Caribe contra la trata de esclavos. Sea como sea, el comercio en Sab, la política en Amalia, la educación en María, la investigación académica en El inglés de los güesos o un nuevo auto Sunbeam en La casa de los espiritus, cualquier contacto con los ingleses nunca termina bien.

La guerra del fin del mundo recoge el tema de la intervención inglesa a través de la historia económica y militar de Hispanoamérica. Las constantes sospechas de una conspiración inglesa que nunca se comprueba enfatizan que los ingleses no tienen que estar presentes para controlar a sus súbditos. En La casa de los espiritus Allende expone y luego de-construye la economía neocolonialista inglesa. Muestra con barcos, ferrocarriles, hoteles, escuelas, autos, ropa, muebles y porcelana pintada a mano que la cultura y economía inglesas se infiltraban en cada región de la sociedad chilena. Tal situación sentó las bases para la rebelión popular al final y últimamente la destrucción de la clase dirigente anglófila. Cuando el museo inglés compra el arte familiar de la rebelde Alba el círculo vicioso se rompe y América finalmente se libera de dos siglos bajo el imperio invisible británico.

\section{Referencias}

Allende, I. (1982). La casa de los espíritus (9. a ed.). Barcelona: Plaza \& Janes.

Bello, A. (1826). «Silva a la agricultura en la zona tórrida». Recuperado de www. wikisource.org

Carpentier, A. (1999). El arpa y la sombra (18. a ed.). México: Siglo XXI.

Carpentier, A. (2013). El reino de este mundo. México, D.F.: Lectorum.

De Castellanos, J. (1589). Discurso del Capitán Francisco Draque de nación inglés. En A. González Palencia. Madrid: Instituto de Valencia.

De Herrera, A. (1601-1615). Historia general de los hechos de los Castellanos en las islas i tierra firme del mar oceano. Madrid: Imprenta Real Juan Flamenco, Juan de la Cuesta

Echeverría, E. (1982). El matadero. En H. Vélez Dossman y M. Torres Aparicio (Eds.) Selección del cuento latinoamericano (pp. 9-22). Bogotá: Taller Gráfico.

Fernández, T. (1993). José Mármol. En L. Ínigo Madrigal, Historia de la literatura

54 La amenaza inglesa en la novela hispanoamericana, 1841-1982 Charles B. Moore 
hispanoamericana (2. ${ }^{a}$ ed., tomo II, pp. 155-162). Madrid: Cátedra.

French, J. (2005). Nature, Neo-Colonialism, and the Spanish American Regional Writers. Hanover, NH: UP of New England.

García-Márquez, G. (1992). Cien años de soledad (85. a ed.). Buenos Aires: Sudamericana.

Gates, E. (1961). Charles Darwin and Benito Lynch's El inglés de los güesos. Hispania 44(2), 250-253.

Gómez, G. (2008). Sab. Barcelona: Linkgua.

González, A. (1589). Prólogo. En J. de Castellanos, Elegías de varones ilustres de Indias. (pp. VII-CXVIII). Madrid: Instituto de Valencia.

Head, G. (1971). El extranjero en las obras de Benito Lynch. Hispania 54(1), 91-97.

Hernández, J. (1973). Martín Fierro (18. ${ }^{\mathrm{a}}$ ed.). Buenos Aires: Losada.

Hidalgo, D. (2007). The Evolution of History and the Informal Empire: La Decena Trágica in the British Press. Mexican Stu dies/Estudios Mexicanos 23(2), 317-354.

Ibarra, R. (2011). Gómez de Avellaneda's Sab: A Modernizing Project. Hispania 94(3), 385-395.

Isaacs, J. (1982). Maria (9. ${ }^{\text {a }}$ ed.). Buenos Aires: Losada.
Lynch, B. (2004). El inglés de los güesos. Buenos Aires: Editorial Troquel.

Mandrell, J. (1990). The Prophetic Voice in Garro, Morante, and Allende. Comparative Literature 42(3), 227-246.

Mármol, J. (1955). Amalia (tomos I y II). Buenos Aires: Ediciones Estrada.

Peralta, P. (1732). Lima fundada (tomos I y II). Lima: Francisco Sobrino y Bados. Recuperado de https://archive.org/ details/JohnCarterBrownLibrary.

Pratt, M. (2008). Imperial Eyes (2. ${ }^{a}$ ed.). New York: Routledge.

Torres, E. (1976). Actitud frente a la vida de los personajes en El inglés de los güesos de Benito Lynch. Explicación de Textos Literarios 5(1), 13-22.

Vargas-Llosa, M. (1991). La guerra del fin del mundo (2. ${ }^{\text {a }}$ ed.). Barcelona: Biblioteca del Bolsillo. . (1999). La casa verde. Madrid: Grupo Santillana.

Villaverde, C. (1986). Cecilia Valdés (3. ${ }^{\text {a }}$ ed.). México: Porrúa.

Ward, T. (2002). Gertrudis Gómez de Avellaneda's Sab: A Cuban Novel in a Latin American Context. Recuperado de www. academia.edu.

Winn, P. (1976). British Informal Empire in Uruguay in the 19th Century. Past and Present 73, 100-126. 